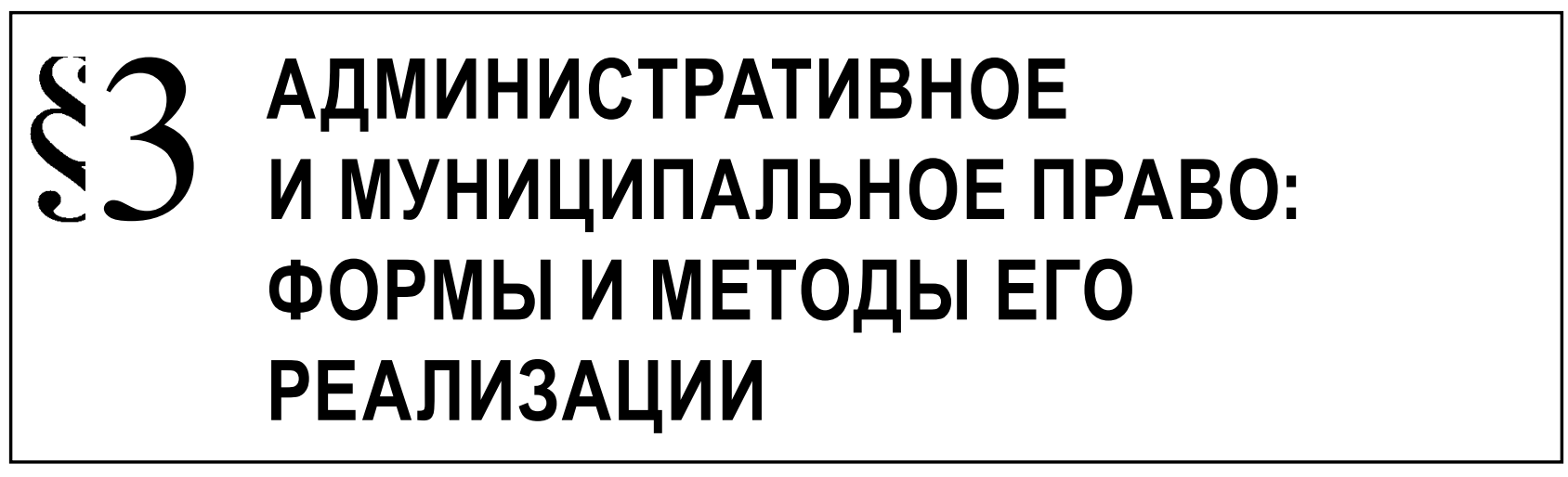

Чежидова А.В.

\title{
ОТКРЫТОСТЬ КАК НЕОБХОДИМОЕ УСЛОВИЕ ДЕЯТЕЛЬНОСТИ КОНТРОЛЬНО-НАДЗОРНЫХ ОРГАНОВ ИСПОЛНИТЕЛЬНОЙ ВЛАСТИ
}

Аннотация: Предметом исследования являются теоретические положения, сформулированные в административном праве и теории государственного управления, связанные с обеспечением открытости деятельности органов исполнительной власти, осуществляющих государственные функции по контролю и надзору; нормативные правовые акты, регулирующие вопросы открытости деятельности контрольно-надзорных органов исполнительной власти; правовые и организационные механизмы, включающие в себя средства (инструменты) и мероприятия (меры), направленные на обеспечение открытости контрольно-надзорных органов исполнительной власти; правоприменительная деятельность контрольно-надзорных органов исполнительной власти, которая обусловлена реализацией механизмов открытости и влияние ее на эффективную работу указанных органов. Методологическую основу исследования составили общенаучные и специальные методы познания. В ходе исследования применялись общенаучные методы, такие как диалектический, логический, и частно-научные: формально-юридический, прогностический, конкретно-социологический, сравнительно-правового анализа, системно-структурный и другие. В целом при проведении исследования использовался комплекс различных методов. Такой подход направлен на достижение объективности выводов и является одним из условий решения задач и достижения чели исследования. Различные вопросы правового регулирования и правоприменительной деятельности органов исполнительной власти были предметом изучения различных ученых в области административного права и процесса. Детально исследовались теоретические основы построения системы контрольно-надзорных органов исполнительной власти, принципы их деятельности, субъекты контрольно-надзорных правоотношений, процедурные вопросы осуществления мероприятий по контролю и надзору. Учеными предлагались различные мероприятия организационно-правового характера, направленные на совершенствование деятельности контрольно-надзорных органов, а также концептуальные основы для реформирования в целом действующей системы государственного контроля и административного надзора.Признавая вклад названных и других ученых в исследование отдельных вопросов развития системы государственного контроля и надзора, следует констатировать, что в настоящее время отсутствует комплексное научное исследование, посвященное правовым и организационным вопросам обеспечения открытости контрольно-надзорных органов исполнительной власти. Данная диссертация направлена на восполнение этого пробела.

Ключевые слова: Исполнительная власть, государственный надзор, открытость государственных органов, средства массовой информации, гражданское общество, контрольно-надзорный орган, информационное общество, коррупция, публичное управление, информация.

Review: The work of regulatory authorities is a priority for any modern state. During the last decade the Russian Federation is trying to improve the enforcement agencies by conducting large-scale administrative reforms, introduction of modern governance mechanisms and use of experience of the advanced Western countries. There is no doubt that the effectiveness of supervisory bodies depends not only on security and law and order, protection of rights and freedoms of 
citizens, their social well-being, but, importantly, on the decrease of corruption and crime in the country, as ineffective and corrupt practices of enforcement agencies damage the economy of the country, the development of small and medium-sized businesses, destroy the initiative of the population in the development of various social processes aimed at improvement of the welfare of our country, and are of great distrust and disrespect for the public authorities and their officials.The solution of these most difficult tasks is impossible without close cooperation of public authorities and civil society. Therefore, the duty of the state is to create the necessary mechanisms for such collaboration, to secure them in the current legislation and to ensure the correct implementation of the established principles and rules.

Keywords: supervisory body, civil society, mass media, transparency of pubic authorities, government supervision, Executive power, information society, corruption, public administration, information.

$\mathrm{C}$ овременное государственное управление в XXI должно способствовать развитию множество процессов, происходящих в обществе и государстве. Не может считаться эффективным государственное управление, если оно не обеспечивает защиту конституционных прав и свобод граждан, безопасность и правопорядок, законность демократических институтов, реализацию экономических свобод и свободу рынка, справедливость и обоснованность решений, принимаемых органами государственной власти, и многие другие социальные ценности и устои, к которым уже привыкло современное общество.

Переход от советской системы государственного управления к открытому государственному управлению потребовало несколько десятилетий и принятия непростых политических, экономических и юридических решений со стороны руководства страны. Новая система государственного управления должна быть прежде всего открытой для общества и каждого гражданина, чтобы решения органов государственной власти и их должностных лиц были понятными, прозрачными и не вызывали сомнения.

Совершенно очевидно, что в эпоху развитых информационных технологий, образования информационного общества XXI века, невозможно сохранять в закрытом режиме деятельность органов государственной власти. К открытости государственного управления стремятся большинство развитых стран, международные организации и мировое сообщество в целом.

Как отмечается многими учеными, «понятие «информационное общество» прочно вошло в жизнь многих стран. Одна из задач информационного общества - дать право всем его гражданам на доступ к информации и знаниям. Отсюда общий подход: информация, создаваемая государственными органами во всех сферах и на всех уровнях, должна быть доступной для населения, а любые официальные запреты на такой доступ должны особым образом обосновываться и за- трагивать как можно меньшую часть этой информации»[1].

Открытость государственного управления или органов государственной власти позволяет решать такие сложные и важные проблемы, как неэффективность принимаемых решений органами государственной власти и их должностными лицами, коррупция в государственных органах, незаконная монополистическая деятельность, связь государственных служащих с криминальными структурами, фальсификация избирательных процессов; недобросовестная деятельность участников рынка, функционирование экстремистских и террористических организаций; и др.

Еще более важно отметить, что без необходимой открытости государственного управления вряд ли возможны эффективный общественный контроль органов государственной власти и продуктивное взаимодействие общества и государства.

Стоит констатировать тот факт, что Российская Федерация находится лишь на пути становления и запуска эффективных механизмов, обеспечивающих открытость деятельности органов государственной власти и местного самоуправления. В частности, это касается контрольных и надзорных органов, оказывающих серьезное воздействие, а порой и давление, на все сферы жизнедеятельности. Избыточное и неправомерное давление контролирующих и надзирающих органов на субъекты экономической деятельности не позволяет развиваться экономике страны, образует непреодолимую череду коррупционных барьеров, которые уничтожают всякое желание у активного населения заниматься предпринимательской деятельностью или любой другой социально-значимой деятельностью, направленной на благо нашей страны.

Подтверждением этому являются как внешние, так и внутренние независимые исследования, проводящие российскими и международными организациями.

Так, согласно рейтингу Heritage Foundation, определяющему уровень экономической слободы 
в стране, Россия входит в список стран с наименьшей степенью экономической свободы. В 2014 году по этому показателю она заняла 143-е место из 178 стран, набрав 52,1 балла из 100 возможных. В этот раз Россия оказалась по уровню экономической свободы между Коморскими Островами и Гвинеей. Таджикистан, для сравнения, находится на 140 -й строчке, Либерия - на 141-й. Среди 43 европейских стран Россия заняла 41-е место. По степени экономической свободы Россия упала ниже партнеров по БРИКС: Бразилия заняла в нем 118-е место, Индия - 128-е, Китай - 139-е, ЮАР -72-е[2].

Индекс экономической свободы рассчитывается по среднему арифметическому десяти контрольных показателей: право собственности, участие правительства, свобода от коррупции, фискальная, монетарная и финансовая свобода, а также свобода предпринимательства, труда, торговли, инвестиций. По каждому показателю странам выставляется оценка в баллах - от 0 до 100. Чем больше баллов, тем более высоко оценивается уровень экономической свободы в стране по этому критерию. При итоговом расчете индекса показатели суммируются[3].

По мнению экспертов Heritage Foundation, проводивших исследование, «фактически Россия в последние годы топчется на месте, передвигаясь в рейтинге то вниз, то вверх на нескольких соседних позиций. Российское законодательство представляет угрозу для иностранных инвесторов... Маленький, неразвитый финансовый сектор остается уязвимым для государственного влияния. Россия для иностранных инвесторов представляется закрытой страной с высоким уровнем коррупции, несправедливыми судами и неудобным для работодателя законодательством. Защита собственности слабая. Правоохранительная система коррумпирована. Ограничения на экспорт и импорт, непрозрачные правила и стандарты...»[4].

Согласно индексу GRICS (Governance Research Indicator Country Snapshot), который определяется 1 раз в 2 года Всемирным Банком и оценивает эффективность государственного управления в 209 странах, Россия по таким показателям, как эффективность работы правительства, качество законодательства, верховенство закона и контроль за коррупцией, находится в нижней части рейтинга[5]. Последние данные этой организацией были представлены за 2013 год. Они свидетельствуют, что по многим показателям Россия находится в нижнем рейтинге стран, и динамика процессов по каждому из направлений, начиная с 2003 года, только ухудшается[6].
На этом фоне также выглядят неудовлетворительными данные, представленные международной организацией Transparency International (TI) «Транспэренси Интернэшнл», которая рассчитывает индекс восприятия коррупции (Corruption Perceptions Index, CPI). Индекс представляет собой комбинацию опросов, относящихся к сфере коррупции, которые собираются различными организациями, относительно распространенности коррупции в государственном секторе. Так, согласно данным этой организации, Россия в последние годы занимала следующие места: 2011 год - 143 место из 183 стран; 2012 год - 133 место; 2013 год - 127 место.

Столько же баллов, как и Россия, получили Азербайджан, Пакистан, Никарагуа, Мали, Мадагаскар, Ливан, Гамбия и Коморские остова. При этом первое место заняли Дания и Новая Зеландия, второе - Финляндия и Швеция[7].

Таким образом, можно констатировать, что большинство известных международных организаций, проводящих исследования государственного управления в России, ставят страну на последние места в рейтингах, что, скорее всего, обусловлено, не какими-то политическими мотивами, а действительно сложившейся сложной обстановкой отношений между государством и обществом, когда первое не учитывает интересы последнего и движется не в поступательном направлении, а назад, к чрезмерному бюрократизму и полицейскому государству.

Конечно же, следует говорить, что на рейтинг значительным образом влияет именно закрытость органов государственного управления, не позволяющая принимать эффективные управленческие решения, а равно серьезным образом модернизировать и реформировать несовершенную систему государственного управления в Российской Федерации.

Вместе с тем необходимо отметить, что имеющиеся в государственном управлении проблемы, связанные с открытостью органов государственной власти, не остались без внимания ученых, занимающихся вопросами государственного управления, конституционного и административного права.

В научных трудах известных ученых открытость органов государственной власти и местного самоуправления рассматривается как неотъемлемый элемент современного публичного управления.

Традиционным подходом следует считать обозначение гласности в качестве основного принципа публичного или государственного управления, а равно организации и деятельности органов государственной власти и местного самоуправления, 
обеспечивающего их открытость, прозрачность и эффективность.

Профессор Ю.М. Козлов указывал, что открытость достигается посредством реализации принципа гласности, который означает, что «применяемые в порядке административно-правового регулирования общественных отношений нормативные правовые акты, затрагивающие права и свободы граждан, не подлежат применению, если они официально не опубликованы для всеобщего сведения...В процессе формирования норм административного права создаются необходимые возможности для выражения и учета мнения граждан и общественных объединений».

С его точки зрения, гласность как принцип организации и деятельности органов исполнительной власти обеспечивает доступность и открытость деятельности органов исполнительной власти[8].

Как отмечает профессор Ю.Н. Старилов, «административное право, регулируя процедуру государственного управления, должно обеспечивать открытость информации об осуществлении управленческой деятельности. Принцип гласности в системе управления - важнейшая правовая основа выполнения государством провозглашенных целей; этот принцип обеспечивает справедливость и гарантирует возможность обратного влияния граждан на само государство, на его органы исполнительной власти с целью достижения истины и эффективности»[9].

Профессор Ю.А. Тихомиров считает, что открытость в публичном управлении должна обеспечиваться посредством реализации права на доступ к информации из информационных ресурсов. По его мнению, «доступ физических и юридических лиц к государственным информационным ресурсам является основой осуществления общественного контроля за деятельностью органов государственной власти, органов местного самоуправления, общественных, политических и иных организаций, а также за состоянием экономики, экологии и других сфер общественной жизни»[10].

В других научных и учебных работах, посвященных административному праву, также делается акцент на гласность как основу для открытости и эффективности органов исполнительной власти.

Изложенные точки зрения позволяют констатировать несколько важных аспектов, связанных с открытость органов государственного управления.

Во-первых, открытость позволяет государственным органам и должностным лицам полу- чить независимую оценку различных общественных процессов со стороны самого общества, в том числе получить объективную оценку деятельности самих органов государственной власти и их должностных лиц.

Во-вторых, открытость государственного управления является современным и важным признаком демократического и правового государства, так как именно в таких государствах обеспечивается непрерывное взаимодействие со стороны гражданского общества и государственного аппарата, что позволяет учитывать мнение населения и принимать эффективные и обоснованные решения по различным вопросам.

В-третьих, открытость способствует более эффективной защите конституционных прав и свобод граждан, законных интересов юридических лиц и индивидуальных предпринимателей, так как органам государственной власти и должностным лицам невозможно скрыть нарушения прав и свобод, коррупционные связи, а также препятствует совершению противоправных действий.

В-четвертых, открытость неразрывно связана с гласностью, а это означает, что мнение населения должно учитываться при принятии управленческих решений органами государственной власти, население может посредством высказывания своего мнения влиять на принимаемые решения. Кроме того, население и отдельные граждане могут быть инициаторами совершения определенных действий органами государственной власти и их должностными лицами. Плюс ко всему мнение населения может учитываться при оценке деятельности органов исполнительной власти и их должностных лиц, влиять на кадровые решения и направления деятельности государственных структур.

В-пятых, открытость органов государственного управления является важнейшим условием для повышения доверия со стороны населения к органам государственной власти и их должностным лицам. Именно участие населения в различных формах управления делами государства, безусловно, повышает авторитет действующей власти, способствует улучшению взаимодействия населения и государства, и в целом повышает общественное доверие к органам государственной власти[11].

В-шестых, открытость государственного управления способствует осуществлению эффективного общественного контроля. Субъекты общественного контроля в условиях информационной открытости могут получать доступ к необходимой информации о деятельности органов исполнительной 
власти и их должностных лиц, тем самым могут полноценно реализовываться установленные законодательством формы общественного контроля (мониторинг, общественная проверка, общественная экспертиза и др.) и получать достоверные результаты такого контроля, то есть могут быть достигнуты цели и задачи общественного контроля, закрепленные в статье 5 Федерального закона от 21 июля 2014 года №212-Ф3 «Об основах общественного контроля в Российской Федерации».

В-седьмых, посредством открытости государственного управления обеспечивается законность и дисциплина деятельности органов государственной власти и государственных служащих. Наличие открытых данных о деятельности государственных органов, открытых сведений о соблюдении государственными служащими антикоррупционных запретов, открытых отчетов о проделанной работе и устраненных нарушениях дисциплинируют и организуют на законной основе деятельность любого государственного органа и каждого государственного служащего.

В-восьмых, открытость органов государственной власти является необходимым условием для обеспечения взаимодействия и взаимосвязи между обществом и государством. Взаимное влияние как органов государственной власти на граждан, так, наоборот, населения на государство не должно быть односторонним. Делая открытой свою деятельность, государство как бы «приглашает» граждан к взаимодействию, то есть участию в обсуждении принимаемых государственно-управленческих решений. При этом подобное обсуждение гражданами управленческих решений по смыслу и логике не должно сводиться лишь к ничем необоснованной критике или направлению предложений о принятии непродуманных и популистских решений. Конструктивизм заключается в том, что граждане берут на себя ответственность добросовестно участвовать в открытых формах государственного управления; они должны быть неангажированными и независимыми в ходе участия в деятельности государственных органов (не зря к работе привлекаются именно независимые эксперты); направляемые ими предложения и замечания должны быть направлены на улучшение и совершенствование государственного управления; использование информации не должно быть направлено в политических целях или в ущерб национальной безопасности страны.

В-девятых, открытость органов государственной власти и их должностных лиц способствует бо- лее эффективному разрешению публично-правовых споров. В некоторых случаях отсутствие у гражданина необходимой информации о том, почему государственный орган или должностное лицо приняли именно такое решение, становиться причиной возникновения публично-правового конфликта и дальнейшего обжалования действий и решений органов государственной власти и их должностных лиц. Напротив подробное разъяснение принятых решений органами государственной власти и их должностными лицами, дополнительное взаимодействие с гражданином с целью разъяснения причин возникновения спорной ситуации, является необходимым механизмом позволяющим избежать или предотвратить ненужных и бессмысленных правовых споров, которые могут рассматриваться как в административном, так и в судебном порядке.

И-наконец, в-десятых, открытость государственного управления серьезным образом влияет на качество принимаемых решений органов государственной власти и их должностных лиц. В отсутствие открытости деятельности органов государственного управления вряд ли можно судить о качестве и законности принимаемых решений и совершаемых действий. Если действие или решение принятое должностным лицом никому неизвестно, соответственно, его никто не будет обжаловать или опротестовывать, следовательно, оно и не будет признано незаконным, хотя и может являться таковым. Зачастую внутри одного ведомства или одной государственной структуры, подразделения, руководители и их подчиненные пытаются скрыть от общественности принятые решений, или умышленно не доводить их до всеобщего сведения, что позволяет завуалировать незаконные, неправомерные и необоснованные действия, придать им срытую (латентную) видимость законность, правомерности и обоснованности. Вследствие чего, наступают серьезные неблагоприятные последствия коррупционного характера как для государства, так и для общества, неэффективно расходуются бюджетные средства, неправомерно отчуждается государственное и муниципальное имущество, неэффективно осуществляется кадровая политика, обнуляются социальные льготы граждан, игнорируются поручения и государственные программы принятые высшем руководством страны и т.д.

Все это возможно только в отсутствие открытости деятельности органов государственной власти. Поэтому именно открытость, как никакой другой механизм, позволяет следить и обеспечивать качество принимаемых государственно-управлен- 
Административное и муниципальное право 5 (89) 2015

ческих решений. Особенно это влияет на качество при принятии решений о приватизации государственного имущества, дебюрократизации государ- ственного аппарата, дерегулировании отдельных сфер государственного управления, прежде всего, в экономике.

\section{Библиография:}

1. Гражданин, закон и публичная власть. - М.: Норма, 2005. С.157

2. Россия свободна о свободы. Россия в рейтинге экономических свобод между Коморами и Гвинеей // Газета.Ru. 2015. 28 января (http://gazeta.ru/business/2015/01/28/6390417.shtml

3. Николаев И. В рейтинге экономической свободы Россия заняла 140-е место // Российская газета. 2014. 21 янваpя. (http://www.rg.ru/2014/01/21/rossiya.html

4. Россия свободна о свободы. Россия в рейтинге экономических свобод между Коморами и Гвинеей // Газета.Ru. 2015. 28 января (http://gazeta.ru/business/2015/01/28/6390417.shtml

5. Распоряжение Правительства РФ от 25 октября 2005 г. №1789-р (в ред. от 10.03 .2009 г.) «0 Концепции административной реформы в Российской Федерации в 2006 - 2010 годах» // СЗ РФ. 2005. №46. Ст.4720.

6. Worldwide Governance Indicators, 2013 // http://info.worldbank.org/governance/wgi/index.aspx\# countryReports

7. Индекс восприятия коррупции - 2013: усилий власти недостаточно, чтобы изменить положение. Официальный сайт Трансперенси Интернешнл Россия // http://www.transparency.org.ru/indeks-vospriiatiia-korruptcii/zastriali.

8. Козлов Ю.М. Административное право: Учебник. - М.: Юристъ, 2007. С.246.

9. Старилов Ю.Н. Административное право: В 2 ч. Ч.1: История. Наука. Предмет. Нормы. - Воронеж: ВГУ, 1998. С. 361-362.

10. Тихомиров Ю.А. Современное публичное право: монографический учебник. - М.: Эксмо, 2008. С.111.

11. Общественное доверие к органам государственной власти: выявление проблем и предложения по их решению: Научно-практическое пособие / Под ред. А.В. Мартынова. - Н.Новгород: Изд-во Нижегородского государственного университета им. Н.И. Лобачевского, 2013. - 210 с.

\section{References (transliterated):}

1. Grazhdanin, zakon i publichnaya vlast'. - M.: Norma, 2005. S.157

2. Rossiya svobodna o svobody. Rossiya v reitinge ekonomicheskikh svobod mezhdu Komorami i Gvineei // Gazeta.Ru. 2015. 28 yanvarya (http://gazeta.ru/business/2015/01/28/6390417.shtml

3. Nikolaev I. V reitinge ekonomicheskoi svobody Rossiya zanyala 140-e mesto // Rossiiskaya gazeta. 2014. 21 yanvarya. (http://www.rg.ru/2014/01/21/rossiya.html

4. Rossiya svobodna o svobody. Rossiya v reitinge ekonomicheskikh svobod mezhdu Komorami i Gvineei // Gazeta.Ru. 2015. 28 yanvarya (http://gazeta.ru/business/2015/01/28/6390417.shtml

5. Rasporyazhenie Pravitel'stva RF ot 25 oktyabrya 2005 g. №1789-r (v red. ot 10.03 .2009 g.) «0 Kontseptsii administrativnoi reformy v Rossiiskoi Federatsii v 2006 - 2010 godakh» // SZ RF. 2005. №46. St.4720.

6. Worldwide Governance Indicators, 2013 // http://info.worldbank.org/governance/wgi/index.aspx\# countryReports

7. Indeks vospriyatiya korruptsii - 2013: usilii vlasti nedostatochno, chtoby izmenit' polozhenie. Ofitsial'nyi sait Transperensi Interneshnl Rossiya // http://www.transparency.org.ru/indeks-vospriiatiia-korruptcii/zastriali.

8. Kozlov Yu.M. Administrativnoe pravo: Uchebnik. - M.: Yurist", 2007. S.246.

9. Starilov Yu.N. Administrativnoe pravo: V 2 ch. Ch.1: Istoriya. Nauka. Predmet. Normy. - Voronezh: VGU, 1998. S. 361-362.

10. Tikhomirov Yu.A. Sovremennoe publichnoe pravo: monograficheskii uchebnik. - M.: Eksmo, 2008. S.111.

11. Obshchestvennoe doverie $\mathrm{k}$ organam gosudarstvennoi vlasti: vyyavlenie problem i predlozheniya po ikh resheniyu: Nauchno-prakticheskoe posobie / Pod red. A.V. Martynova. - N.Novgorod: Izd-vo Nizhegorodskogo gosudarstvennogo universiteta im. N.I. Lobachevskogo, 2013. - 210 s. 